\title{
Correspondence
}

\section{Erosion of urethra in female patients with spinal cord injury}

Spinal Cord (2005) 43, 451. doi:10.1038/sj.sc.3101728; Published online 15 February 2005

Bycroft et $a l^{1}$ present an interesting case of erosion of penile skin and underlying urethra due to badly applied condom in a male patient with spinal cord injury. Erosion of urethra can occur in female patients as well. In these cases, erosion occurs usually at the bladder neck region. The balloon of the Foley catheter can cause pressure necrosis when the catheter is pulled inadvertently (Figure 1). Reznicek ${ }^{2}$ recommended the use of the smallest catheter and the smallest balloon possible $(5 \mathrm{ml})$, as smaller balloons prevent erosion of bladder neck. The catheter tubing should be attached firmly but without tension to the thigh or the abdomen, and preferably, the attachment site is rotated each day. In the spinal cord injury patient shown in the illustration, the catheter is pulled tightly because the catheter (not the tubing) is attached to the thigh strap, and there is no leeway to the catheter. Especially, when the thigh is abducted and externally rotated in order to avoid pressure on the contralateral ischial tuberosity, traction on Foley catheter becomes exaggerated, as indeed happened in the patient shown in the illustration.

In another female patient with paraplegia at D-7 level, the balloon of the Foley catheter eroded the urethra right through to the symphysis pubis. This patient required ileal loop urinary diversion. Subsequently, this patient developed bilateral hydronephrosis and later on, vitamin B-12 deficiency. The series of complications, which this patient suffered from, could have been averted had attention been paid in the beginning to management of the neuropathic bladder.

Erosion of urethra due to long-term Foley urethral catheter drainage is preventable and spinal cord clinicians must be proactive to avert these complications. $^{3}$ The health professionals must exercise great care to prevent any traction on Foley balloon when spinal cord injury patients are positioned to relieve pressure on vulnerable sites, for example, sacrum or ischial tuberosity. As emphasised by Bycroft and associates, intermittent catheterisation should be practised instead of long-term urethral catheter drainage whenever feasible. ${ }^{1}$ Spinal cord clinicians may take a leading role in educating patients, carers and health professionals (both in the spinal injury centres and in the community), for example, how to avoid traction on Foley balloon while positioning patients with long-term urethral catheter drainage. Although care of Foley catheter or penile

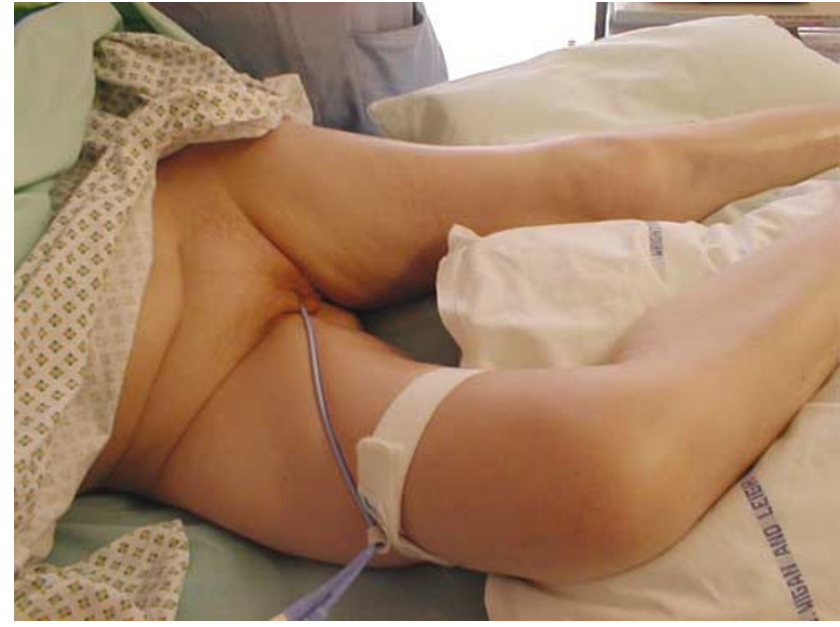

Figure 1 Clinical photograph of a spinal cord injury patient with long-term urethral Foley catheter drainage: the catheter is pulled so tightly that it has caused a deep groove on the thigh. What is not visible is the damage done to the bladder neck and proximal urethra due to traction on the balloon of Foley catheter. If such a forceful pull on Foley catheter is continued for significant period, there will be pressure necrosis of bladder neck and proximal urethra. This photograph was taken after obtaining informed consent from the patient

sheath may appear too simplistic, serious complications will be prevented if attention is paid to details.

S Vaidyanathan ${ }^{1}$, BM Soni ${ }^{1}$, E Brown ${ }^{1}$ and G Singh ${ }^{1}$

${ }^{1}$ North West Regional Spinal Injuries Centre, District General Hospital, Town Lane, Southport, UK

\section{References}

1 Bycroft J, Hamid R, Shah PJ. Penile erosion in spinal cord injury - an important lesson. Spinal Cord 2003; 41: 643-644.

2 Reznicek SB. Common urologic problems in the elderly. Postgraduate Med 2000. http://www.postgradmed.com/ issues/2000/01_00/reznicek.htm.

3 Vaidyanathan S, Mansour P, Soni BM, Singh G, Watt JW, Sett P. Should spinal cord clinicians be proactive in preventing spinal cord injuries and decreasing secondary complications caused by spinal cord injury? Spinal Cord 2003; 41: 475-477. 